\title{
EL VOTO ELECTRÓNICO Y EL TEST DE CALIDAD; O DE CUATRO BODAS COMPLICADAS Y UN POSIBLE FUNERAL
}

\author{
LUIS A. GÁLVEZ MUÑOZ \\ y
}

JOSÉ GABRIEL RUIZ GONZÁLEZ 


\section{SUMARIO}

I. LAS DUDAS DEL LEGISLADOR ANTE EL VOTO ELECTRÓNICO. II. EL TEST DE CALIDAD COMO ESCRUTINIO DE ACEPTABILIDAD DEL VOTO ELECTRÓNICO. A) Seguridad o fiabilidad técnica. B) Garantía de los principios básicos del sufragio. C) Integración armónica en el régimen electoral. D) Consenso o aceptación por parte de los implicados. E) Limitación de costes. III. LAS POSIBILIDADES DE IMPLANTACIÓN DEL VOTO ELECTRÓNICO: RETOS Y ESTRATEGIAS. IV. BIBLIOGRAFÍA CITADA. 


\title{
EL VOTO ELECTRÓNICO Y EL TEST DE CALIDAD; O DE CUATRO BODAS COMPLICADAS Y UN POSIBLE FUNERAL
}

\author{
POR \\ LUIS A. GÁLVEZ MUÑOZ \\ Profesor Titular de Derecho Constitucional. Universidad de Murcia \\ $\mathrm{y}$ \\ JOSÉ GABRIEL RUIZ GONZÁLEZ \\ Profesor Colaborador Honorario. Universidad de Murcia
}

\section{LAS DUDAS DEL LEGISLADOR ANTE EL VOTO ELECTRÓNICO ${ }^{1}$}

El voto electrónico carece en España de implantación alguna. Nos encontramos ante un fenómeno global ${ }^{2}$, que se halla presente en países de todas las latitudes y

1 Este trabajo se enmarca dentro del proyecto de investigación «El régimen jurídico de la jornada electoral» (Código DER2009-13249/JURI), subvencionado por el Ministerio de Ciencia e Innovación.

2 Vid. PRESNO LINERA, M. A. (2007). «La globalización del voto electrónico», en COTINO HUESO, L. (coordinador), Democracia, participación y voto a través de las nuevas tecnologías, Granada, Comares, págs. 341 y ss. 
niveles de desarrollo, algunos muy próximos a España, como Alemania, Francia o Bélgica, pero que, sin embargo, no ha terminado de cuajar entre nosotros.

Esto no significa, en modo alguno, que los poderes públicos de nuestro país hayan permanecido indiferentes hacia este movimiento legislativo en pro del voto electrónico. Nada estaría más lejos de la realidad. Los poderes públicos españoles han desarrollado, por el contrario, una intensa labor en orden a la posible implantación del voto electrónico en las diversas elecciones y referendos políticos. Así: diversos organismos estatales y, en algún caso, autonómico, han realizado o impulsado la realización de interesantes estudios sobre el voto electrónico, en los que se ha analizado sus ventajas, inconvenientes y posibilidades de su introducción ${ }^{3}$; el Ministerio del Interior y algunas Consejerías autonómicas con competencias en materia electoral han llevado a cabo numerosos y muy diferentes ensayos o pruebas de voto electrónico, con relevantes resultados ${ }^{4}$; finalmente, hay que tener presente que el Parlamento Vasco aprobó a fines del siglo pasado una reforma de la Ley Electoral autonómica ${ }^{5}$, por la que se introducía un procedimiento de voto electrónico presencial en las elecciones a la Cámara vasca, si bien esta regulación no ha tenido aplicación alguna y no es previsible tampoco que la pueda ya tener, pues se halla inmersa en un proceso de evaluación y revisión por parte de las fuerzas políticas vascas ${ }^{6}$.

3 Es el caso, por ejemplo, del informe que el Consejo de Estado realizó en 2009, a petición del Gobierno, sobre la reforma del régimen electoral general, incluyendo, entre otras cosas, el estudio del voto electrónico. Vid. VV.AA. (2009). El Informe del Consejo de Estado sobre la reforma electoral. Texto del Informe y debates académicos, Madrid, Consejo de Estado y Centro de Estudios Políticos Constitucionales, págs. 264-266.

4 Hay que destacar la riqueza y variedad de estos ensayos: han tenido lugar en diversas zonas del país, en épocas distintas, a iniciativa de diversas Administraciones, en relación con elecciones de todo tipo y referendos, implicando tanto a los electores residentes como a los residentes en el exterior (inscritos en el Censo Españoles Residentes Ausentes, CERA), y afectando a todas las modalidades de voto electrónico (presencial y remoto; por pantalla táctil y urna electrónica; por internet y SMS). Sobre las experiencias de voto electrónico realizadas en España vid. en general, GONZÁLEZ DE LA GARZA, L. M. (2008). El voto electrónico por internet, Constitución y riesgos para la democracia, Madrid, Edisofer, págs. 148 y ss.; y VV.AA. (2009). El Informe del Consejo de Estado sobre la reforma electoral. Texto del Informe..., op. cit., págs. 255-260.

5 Ley 15/1998, de 19 de junio, de modificación de la Ley 5/1990, de 15 de junio, de Elecciones al Parlamento Vasco.

${ }^{6}$ Vid. GÁLVEZ MUÑOZ, L. A. (2009). «Reflexiones sobre el voto electrónico en las elecciones autonómicas», en GÁLVEZ MUÑOZ, L. A. (dir.), El Derecho electoral de las Comunidades Autónomas. Revisión y mejora», Madrid, Centro de Estudios Políticos y Constitucionales, págs. 196-198; vid. también los trabajos de FERNÁNDEZ RIVEIRA, R. Ma: (2001). «El voto electrónico: el caso vasco», Revista de Estudios Políticos, núm. 112, págs. 199-236; y (2005). «El incierto potencial derivado de la conjunción derecho de voto y nuevas tecnologías. El nuevo proyecto de ley de voto 
Habida cuenta de las diversas actividades desplegadas por los poderes públicos en relación con el voto electrónico, cabe preguntarse por el motivo al que obedecen y los objetivos que las guían. Dicho de otra forma, se trata de saber por qué se han planteado los poderes públicos implantar el voto electrónico en España.

Es difícil adentrarse en la mente de una organización, pero parece que el interés demostrado por la Administración hacia el voto electrónico se debe a dos razones fundamentales:

a) La primera, y que es la menos importante, es que el voto electrónico es el voto propio de la era actual. Su establecimiento parece, ciertamente, inevitable, habida cuenta del progresivo e irrefrenable proceso de tecnificación de la sociedad en sus más diversos ámbitos, incluso en los más cotidianos y próximos al ciudadano, como pagar la compra, sacar dinero del banco o acceder al sistema sanitario.

La tecnología está en todas partes y no parece que tenga mucha lógica que el ejercicio del derecho de sufragio se convierta en una excepción ${ }^{7}$. Por otra parte, el voto electrónico se ha utilizado ya con éxito en procesos electorales de organizaciones diversas, como en elecciones a rector de universidad, a juntas de accionistas o al Consejo Asesor de la Guardia Civil.

b) La segunda razón, y más relevante, es que el voto electrónico presenta, en principio, importantes ventajas respecto del voto tradicional en papel, como facilitar el sufragio de ciertos colectivos ciudadanos, reducir los gastos electorales, evitar el despilfarro del papel, eliminar los conflictos sobre validez de determinadas papeletas o agilizar el recuento de los sufragios. Con el voto electrónico se puede conseguir lo mismo que con el voto en papel, esto es, que los ciudadanos ejerzan su derecho de sufragio, pero, muy posiblemente, de forma más eficaz y eficiente. $\mathrm{Y}$ es que el voto en papel no es tan «inocuo» como puede parecer a primera vista. Plantea numerosos problemas, y de muy diverso tipo, que el voto electrónico puede, a priori, resolver. Así:

- El elevado coste económico, derivado de la impresión y distribución de millones de sobres y papeletas, la inmensa mayoría de los cuales no llegan a ser usados. En unas elecciones generales se imprimen por la Ad-

\footnotetext{
electrónico en Euskadi», en Nuevas Políticas Públicas: Anuario multidisciplinar para la modernización de las Administraciones Públicas, núm. 1, (ejemplar dedicado a Los derechos fundamentales y las nuevas tecnologías), págs. 345-369.

7 Estamos inmersos en la era tecnológica, habiéndose extendido, con cierto éxito, las expresiones «homo tecnologicus» $\mathrm{y}$ «homo digitalis».
} 
ministración más de 900 millones de papeletas, a lo que hay que sumar los sobres que imprime la Administración, así como las papeletas y sobres que imprimen los partidos.

- El alto coste ambiental que supone el uso de tanto papel. Estamos hablando de decenas de miles de árboles ${ }^{8}$.

- El ingente esfuerzo organizativo que han de desplegar los poderes públicos, en cuanto que deben confeccionar las papeletas de votación en plazos muy breves y distribuirlas con posterioridad en las casi 60.000 Mesas Electorales que se constituyen en cada elección nacional ${ }^{9}$.

- El riesgo de manipulación de las elecciones mediante la impresión dolosa de papeletas erróneas por parte de alguna persona u organización determinada o la distribución de las papeletas de una circunscripción en otra.

- El peligro de nulidad de votos por introducción de marcas, anotaciones o realización de otras alteraciones por parte del elector e incluso por la utilización de papeletas con diferencias respecto de las oficiales.

- La dificultad de distribuir de forma adecuada las papeletas de votación en los colegios electorales en el supuesto de coincidencia de elecciones.

- La enorme carga de trabajo que supone el cómputo de los votos por las Mesas Electorales, especialmente en caso de coincidencia de procesos electorales o de celebración de elecciones con listas abiertas, como son las del Senado.

Los argumentos parecen consistentes. Y, si esto es así, surge de inmediato una nueva y comprensible cuestión: ¿por qué no se decide de una vez el legislador a implantar el voto electrónico en España?

La pregunta parece absolutamente pertinente. Llevamos más de quince años haciendo estudios y pruebas sobre este instrumento de votación, pero, en verdad, no se ha dado ni un solo paso firme de cara a la implantación efectiva del voto electrónico. ¿Por qué no se pasa ya a la siguiente fase?

La respuesta no parece complicada. El voto electrónico tiene, indudablemente, ventajas, pero también presenta problemas, y el legislador no está seguro de que las ventajas puedan superar a los problemas. Hay una justificada in-

8 Una sola cifra: el Estado imprimió 908 millones de papeletas en las últimas elecciones generales de 2008, lo que supone 1.589 toneladas de papel, y que equivale a 22.000 árboles adultos, de 20 centímetros de diámetro y 25 metros de altura. Además, a ello habría que sumar los sobres que imprime el Estado y las papeletas y sobres que imprimen los partidos.

9 Así, en las elecciones legislativas generales de 9 de marzo de 2008 se establecieron 59.346 Mesas Electorales en todo el territorio nacional, situadas en 35.586 Secciones Electorales. 
certidumbre sobre lo que puede suceder con el voto electrónico ${ }^{10}$. Hay miedo de que el sistema falle, de que surja un problema en su aplicación y se genere entre los partidos y la ciudadanía una desconfianza sobre la pureza de los resultados electorales.

La inactividad legislativa obedece, pues, a una actitud de mera prudencia. Si no se está seguro de poder mejorar algo lo mejor, por decirlo así, es no tocarlo y, mientras tanto, parece una buena decisión hacer estudios y ensayos y observar lo que hacen otros.

¿Y cuáles son esos problemas? El principal problema es el del riesgo de manipulación de las urnas o comunicaciones electrónicas y, al hilo de ello, la pérdida de confianza de los ciudadanos en la pureza de los resultados electorales, pero hay muchos más, como el peligro de fallos en la atribución de los votos, la posibilidad de borrado accidental de los sufragios o el déficit tecnológico de que adolece una parte de la población, especialmente la de más edad y la más pobre ${ }^{11}$.

Los problemas son, por otra parte, muy distintos según se opte por implantar el voto electrónico en los colegios electorales o por hacerlo en la modalidad a distancia, por internet; tienen mucha mayor entidad en este segundo supuesto, habida cuenta la falta de control directo sobre el ejercicio del voto y la necesidad de montar una infraestructura de seguridad y comunicación más amplia y compleja. Tendremos ocasión de comprobarlo en el siguiente apartado, dedicado al estudio de las condiciones requeridas para poder implantar de modo adecuado el voto electrónico ${ }^{12}$.

\section{EL TEST DE CALIDAD COMO ESCRUTINIO DE ACEPTABILIDAD DEL VOTO ELECTRÓNICO}

El reconocimiento de que el voto electrónico presenta problemas serios para el correcto desenvolvimiento del proceso de votación no debe suponer, sin más, el descarte de su implantación. Y es que los problemas citados pueden reducirse

10 Vid. RENIU VILAMALA, J. M . (2008). «Ocho dudas razonables sobre el voto electrónico», en Revista de Internet, Derecho y Política, núm. 6.

11 Es el problema de la «brecha digital», el digital divide que se puso de manifiesto desde muy temprano en las experiencias de voto electrónico realizadas en los Estados Unidos. Ello se ha traducido incluso en demandas ante tribunales por discriminación.

12 Estos problemas pueden reducirse e incluso eliminarse, pero siempre y cuando el voto electrónico se encauce de determinada forma, como veremos luego. 
e incluso eliminarse, siempre y cuando el voto electrónico se encauce de determinada forma.

El estudio de las experiencias extranjeras de voto electrónico, de la literatura sobre el mismo y de los diversos ensayos realizados en España, permiten descubrir, ciertamente, la existencia de una serie de condiciones o variables básicas determinantes de la calidad del voto electrónico y, por tanto, de su aceptabilidad. Se puede hablar, por utilizar un lenguaje cercano y expresivo, del «test de calidad del voto electrónico» ${ }^{13}$.

¿Cuáles son esas condiciones o variables? Pueden exponerse, de forma resumida, en las cinco siguientes:

\section{A) Seguridad o fiabilidad técnica}

La primera condición que se requiere para implantar el voto electrónico es la de la seguridad de las urnas o comunicaciones electrónicas. El voto electrónico debe ir provisto de las garantías técnicas precisas que aseguren la autenticidad de los resultados electorales ${ }^{14}$.

Hay que garantizar técnicamente la limpieza y objetividad de los resultados obtenidos. Las cifras que arroje el proceso de voto electrónico han de ser las correctas. Debemos estar seguros de que el resultado que salga de las urnas electrónicas es el resultado verdadero; que quien ganó las elecciones las ganó realmente.

Esto requiere diseñar y proteger de forma adecuada los canales de emisión, recepción y custodia de los votos. Así:

- En primer lugar, hay que evitar que nadie pueda modificar deliberadamente la información de las urnas electrónicas, esto es, hacer trampas.

- Y, en segundo lugar, hay que garantizar que los votos se graben de forma fiel e, incluso, que ningún accidente pueda producir el borrado o modificación de los datos.

13 No le hemos puesto un nombre definitivo todavía, por lo que, provisionalmente, lo podemos denominar de forma genérica así, como «test de calidad del voto electrónico». Hemos descartado otras metáforas como la de «la prueba del algodón» y otras similares, por ser demasiado coloquiales y estar algo gastadas, aun reconociendo su eficacia.

14 Ésta es la base de la disconformidad mostrada por el Tribunal Constitucional Federal alemán con el sistema de voto electrónico que se utilizaba en Alemania hasta hace poco. Se trata de la Sentencia del Tribunal Constitucional Federal de 3 de marzo de 2009 (BVerfG, 2 BvC 3/07, de 3 de marzo de 2009). Vid. BARRAT ESTEVE, J. (2009). «Observación electoral y voto electrónico», Revista Catalana de Derecho Público, núm. 39, págs. 277 y ss. 


\section{B) Garantía de los principios básicos del sufragio}

El sistema de voto electrónico que se implante debe respetar escrupulosamente los principios fundamentales del sufragio, que están constitucionalmente garantizados. Estos principios son los de universalidad, libertad, igualdad, personalidad y secreto.

Estos principios no se respetan en toda su plenitud en el voto en papel, por lo que su garantía en el voto electrónico parece imprescindible, a fin de mejorar la situación actualmente existente ${ }^{15}$. Ello depende unas veces de la técnica y otras de la organización o diseño que se haga del voto electrónico, como vamos a ver a continuación, aunque con suma brevedad.

a) Universalidad. El reto aquí es facilitar el sufragio. El sufragio universal no supone solamente reconocer el derecho de sufragio de forma generalizada, sino también hacer todo lo posible para que, quienes tienen reconocido el derecho de sufragio, lo puedan efectivamente ejercer.

Para ello, el sistema de voto electrónico que se implante debe cumplir varias condiciones:

- Que sea sencillo de utilizar. Hay que evitar el riesgo de exclusión del proceso electoral de las personas menos familiarizadas con la tecnología.

- Que sea posible obtener ayuda por parte de un funcionario independiente.

- Que sea accesible a los discapacitados. Por ejemplo, los ordenadores y las cabinas de votación deben estar adaptados a las necesidades de estas personas.

Por lo demás, hay que tener en cuenta que el voto electrónico desde cualquier lugar es un factor que en sí mismo facilita el sufragio y contribuye, por tanto, a hacer realidad su universalidad. Por el contrario, en el voto electrónico remoto desde el lugar que se desee es difícil obtener ayuda.

b) Libertad. El sufragio ha de poder confeccionarse en un ambiente de plena libertad, sin riesgo de presión o coacción de ningún tipo. Lo dice, además, de forma expresa el artículo 5 de la LOREG: «nadie puede ser obligado o coaccionado bajo ningún pretexto en el ejercicio del derecho de sufragio».

Esto requiere, fundamentalmente, cuidar las condiciones ambientales en que el elector va a confeccionar el voto. Lo más importante aquí es garantizar o, incluso, exigir, que lo haga en soledad.

15 GÁLVEZ MUÑOZ, L. A. (2009). La confección del voto, Madrid, Centro de Estudios Políticos y Constitucionales. 
Esto es, lógicamente, más fácil de conseguir en el voto electrónico presencial que el voto electrónico remoto, salvo que éste tenga lugar en determinado sitio controlado por las autoridades electorales. Es lo que se llama voto remoto en entorno controlado.

c) Igualdad. Cada elector sólo puede emitir un único sufragio y el mismo sólo debe ser contado una vez. Es la expresión de la conocida y tradicional fórmula «un hombre, un voto».

La garantía de este requisito depende, fundamentalmente, de la técnica; se trata de evitar errores en los programas informáticos, así como de cortar el paso a los posibles intentos fraudulentos de voto múltiple. No obstante, también hay margen de actuación para la organización electoral, en el sentido de impedir que los electores puedan emitir su voto a través de dos sistemas de votación distintos.

d) Personalidad. El voto sólo puede ser emitido por el elector, previamente identificado, y no por cualquier otra persona en su nombre. No hay margen, pues, ni para el voto representativo, ni para el sustitutivo.

Esta es una condición bastante difícil de garantizar en el voto electrónico remoto libre, es decir, desde el lugar que se desee (casa, trabajo, cibercafé, etc.), pues no hay control externo alguno sobre el hecho de que la persona que está emitiendo el voto sea realmente el elector; cabe siempre la posibilidad de apropiación de las claves de acceso de otro, o incluso de la cesión más o menos voluntaria de las mismas. La garantía no es, sin embargo, imposible, pues siempre cabe establecer sistemas de identificación exigentes, como el que se hace por huellas dactilares o por imágenes de retina ${ }^{16}$.

e) Secreto. El sentido del voto emitido por el elector no puede ser conocido por nadie, sin su libre consentimiento. Incluso en algunos casos, ni siquiera con consentimiento del elector; me refiero sobre todo al supuesto en que mostrar el voto pueda servir como justificación de un previo acto de corrupción o coacción ${ }^{17}$.

Esto requiere dos tipos de actuaciones:

- En el plano organizativo hay que colocar de forma adecuada la pantalla de votación; que no pase como en algún ensayo, donde la imagen de la pantalla era visible desde determinadas zonas del local de votación.

- Y en el plano técnico es preciso poner coto a varios peligros: que pueda haber intromisiones informáticas de terceros, es decir, que otras personas puedan espiar la información que se transmite; que sea posible conocer la

${ }^{16}$ Es ésta, sin embargo, una opción poco realista en la actualidad, dado su elevado coste. Además, los sistemas de identificación implantados en la vida social y administrativa giran todos en torno al uso de claves de acceso. Es el caso, por ejemplo, del documento nacional de identidad electrónico. 
secuencia seguida por los electores en la expresión del voto (trazabilidad); y, por último, que se pueda identificar el voto de cada ciudadano a través de los sonidos de radiofrecuencia.

Este requisito es también, igual que la mayoría de los anteriores, más fácil de garantizar en el voto electrónico presencial que en el voto electrónico remoto, especialmente si no hay restricción alguna para elegir el lugar de emisión. En primer lugar, porque sólo en el local electoral el poder público tiene vías para asegurar el secreto; y, en segundo lugar, porque es más sencillo asegurar en él la opacidad de las comunicaciones frente a terceros que en internet.

\section{C) Integración armónica en el régimen electoral}

El voto electrónico no es una pieza independiente del régimen electoral, que pueda contemplarse aisladamente, sino que se inserta en un contexto normativo determinado, en el que, necesariamente, ha de integrarse de la forma más armónica posible. Es preciso, pues, mantener en todo momento, aquí como en otras ocasiones, la coherencia del ordenamiento jurídico.

En ese contexto normativo en el que se inserta el voto electrónico es posible distinguir tres niveles, que, de menor a mayor, y a modo de círculos concéntricos, son: la forma de expresión del voto, el sistema de votación y el régimen electoral. En los tres niveles ha de integrarse el voto electrónico de forma armónica.

Esta integración requiere cambios y novedades de todo tipo en la legislación electoral. Veamos algunos ejemplos:

- Si se implantara el voto electrónico únicamente como voto directo en los colegios electorales, y no como voto a distancia, no tendría mucho sentido que las Mesas Electorales siguieran utilizando las urnas tradicionales para introducir sin más los sufragios emitidos a distancia, sino que lo lógico sería que estos sufragios fueran susceptibles de lectura electrónica, sin necesidad de abrir los sobres, y que la Mesa Electoral los pasara directamente por la máquina de votación, a fin de unificar el modo de escrutinio ${ }^{18}$.

17 Mostrar el voto a otros en el propio local electoral puede constituir también un acto de propaganda o influencia sobre otros, especialmente si lo hace un personaje famoso y la imagen en cuestión la capta un medio de comunicación.

18 Un sistema parecido, aunque más complicado, por implicar la apertura de sobres, es el establecido en la Ley electoral vasca. Así lo establece el artículo 132 quáter, VII: «1. Finalizada la votación pública, el Presidente procederá a introducir en la urna dispuesta para el voto por correo los sobres que contengan las papeletas de votación. 2. Una vez terminada la introducción de los sobres 
- Si se implantara el voto electrónico por internet habría que habilitar centros donde los electores que lo desearan o que no tuvieran acceso a internet pudieran ejercer su sufragio.

- En cualquier caso, habría también que cambiar el modelo de cabina de votación. Tendría que ser más grande y cómoda y que hubiera al menos dos en cada colegio electoral.

- Sería preciso también crear un cuerpo de auxiliares de apoyo en los colegios electorales, a fin de ayudar a los electores a ejercer su voto y resolver las incidencias que se presentaran.

- Habría que eliminar el mailing electoral, así como la financiación del mismo.

- Sería conveniente también introducir cambios en las Juntas Electorales. Al menos, deberían contar con algún órgano técnico de apoyo.

\section{D) Consenso o aceptación por parte de los implicados}

Para poder introducir el voto electrónico es necesario contar con la aceptación de todos o la mayor parte de los sujetos afectados, esto es, partidos y electores. Nos parece imprescindible para que pueda tener éxito.

a) En primer lugar, hay que conseguir el respaldo de los partidos políticos. El voto electrónico afecta a una de los elementos fundamentales del régimen electoral (el sistema de votación) y para introducirlo es preciso que todos los actores políticos estén de acuerdo en ello. Hay que evitar que esta cuestión pueda con-

de votación, el Presidente de la Mesa extraerá de la urna uno a uno dichos sobres. Abriéndolos leerá en voz alta la denominación de la candidatura votada, mostrando la papeleta a los Vocales, a los Interventores y a los Apoderados presentes. 3. A continuación, el Presidente anunciará en voz alta el número total de sobres de votación extraídos de la urna, a fin de que uno de los Vocales de la Mesa entregue al Presidente un número de tarjetas con banda magnética de votación validadas igual al número antes anunciado. 4. Acto seguido, el Presidente, en presencia de los Vocales, de los Interventores y de los Apoderados concurrentes, grabará en la pantalla de votar la tarjeta con banda magnética con la opción contenida en cada papeleta de votación. Seguidamente, introducirá dicha tarjeta grabada en la urna electrónica, procediendo a continuación a destruir la papeleta de votación correspondiente, salvo las declaradas nulas de acuerdo con el número 5 siguiente. Estas operaciones se realizarán sucesivamente con cada una de las tarjetas y de las papeletas del voto por correo. 5. Las papeletas que fueran declaradas nulas por la Mesa, según lo dispuesto en el artículo 115 de la Ley 5/1990, de Elecciones al Parlamento Vasco, habrán de ser rubricadas por los miembros de la Mesa y archivadas en el Acta de la Sesión junto con el resto de la documentación electoral de la Mesa». 
vertirse ab initio en un factor de confrontación política. Si ello ocurriera el fracaso del voto electrónico estaría asegurado.

b) Ahora bien, el apoyo político no es, obviamente, suficiente. El voto electrónico solo puede introducirse y mantenerse si logra, además, la aceptación de los ciudadanos, que son los verdaderos protagonistas del proceso electoral. Para ello es necesario:

- Que vean el voto electrónico como algo próximo, accesible, fácil, cómodo.

- Que se fíen de la técnica, que no tengan dudas sobre la seguridad o sobre el secreto de su sufragio.

- Que comprendan el proceso, lo cual implica que haya publicidad, nada de opacidad ${ }^{19}$. En este sentido es conveniente el uso de software libre, que permite saber cómo se anotan, se suman y se almacenan los resultados.

\section{E) Limitación de costes}

El coste económico es una variable a tener en cuenta en cualquier decisión a adoptar por los poderes públicos y también, cómo no, en la materia en la que nos encontramos ahora. No es cierto, como sostienen algunos, que no se pueda poner precio a los derechos fundamentales ${ }^{20}$. Todo tiene un precio, incluidos los derechos fundamentales, lo que no quiere decir en modo alguno que todos, que todas las personas, lo tengan.

De acuerdo con esta idea, para poder implantar el voto electrónico es necesario que su coste sea socialmente asumible, es decir, no desmedido, proporcional al fin que se persigue. Se trata, dicho de otro modo, de que no se pueda lograr el objetivo perseguido, con estándares de calidad parecida, pero por vías menos costosas en términos económicos.

Esto depende, en buena medida, del diseño que se haga del voto electrónico. No es lo mismo, ciertamente, tener que comprar el software a una empresa que desarrollar uno libre; o tener que implantar una red segura para el voto por internet en unos cuantos locales de cada provincia que poner máquinas de votación en cada colegio electoral.

19 Este argumento ha sido decisivo en la Sentencia del Tribunal Constitucional Federal alemán de 3 de marzo de 2009, ya citada (BVerfG, 2 BvC 3/07, de 3 de marzo de 2009).

${ }^{20}$ Vid., entre otros, HOLMES, S., y SUNTEIN, C. (1999). The cost of rights. Why liberty depends on taxes, New York, W. W. Norton and Company. 
Evidentemente, el coste inicial puede ser elevado. Así, hay que comprar máquinas para votar, cuyo coste es elevado ${ }^{21}$; y, además, hay que llevar a cabo una amplia labor de formación. No obstante, también es cierto que el gasto se puede amortizar en unas pocas elecciones (quizás en tres), entre otras cosas porque muchos instrumentos pueden ser reutilizables y se ahorra mucho en papel y en la distribución del mismo.

\section{LAS POSIBILIDADES DE IMPLANTACIÓN DEL VOTO ELECTRÓNICO: RETOS Y ESTRATEGIAS}

Conocidas, a grandes rasgos, las «condiciones de calidad del voto electrónico», es decir, las variables determinantes de su aceptabilidad, la pregunta que surge de inmediato es la de concretar sus posibilidades de cumplimiento. Se trata de saber si es posible, hoy día, en España, cumplir estas condiciones.

Hay que partir de la advertencia de que el cumplimiento de los requisitos o condiciones de la aceptabilidad del voto electrónico depende, en buena medida, del diseño que se haga del mismo. Cada modalidad de voto electrónico y cada decisión que se adopte en este terreno, plantea ventajas y problemas distintos. No es lo mismo, por ejemplo, el voto electrónico presencial o el voto electrónico remoto; o, dentro de ésta última modalidad, el voto electrónico en un entorno controlado o desde cualquier lugar.

Salvada esta precisión, creemos que es posible afirmar, honestamente, que hoy día en España estamos en condiciones de articular un sistema de voto electrónico que cumpla con todas las condiciones del test de calidad: la tecnología está preparada, como demuestra el éxito de las empresas españolas en este terreno; también lo está la sociedad, como pone de relieve el acceso cotidiano de buena parte de la ciudadanía a la tecnología; y también está a la altura del reto la Administración, que en los últimos años está impulsando decididamente la $A d$ ministración Electrónica ${ }^{22}$.

Se podría decir, pues, que, siempre que el diseño del voto electrónico se haga de determinada forma, como veremos luego, es posible lograr la fiabilidad o seguridad técnica; se pueden garantizar los principios del sufragio; es factible lograr la integración armónica del voto electrónico en el régimen electoral; es po-

21 El coste de un pantalla táctil puede rondar los $900 €$.

22 Vid. GUILLEN CARRAU, J. (2010). «El voto electrónico: régimen electoral o legislación electoral autonómica», Asamblea. Revista Parlamentaria de la Asamblea de Madrid, núm. 23, pág. 160 . 
sible conseguir la aceptación de los sujetos implicados; y se puede, incluso, limitar sus costes.

La variable más difícil de satisfacer es, obviamente, la cuarta, la del consenso político y social y, en particular, la aceptación ciudadana ${ }^{23}$. Es ilustrativo el dato, extraído de las encuestas realizadas en los ensayos, de que un alto porcentaje de electores han expresado su rechazo al voto electrónico (entre 10-15\%), y otro porcentaje muy parecido ha expresado su mayor confianza en el voto en papel ${ }^{24}$.

De aquí, precisamente el extraño subtítulo del presente trabajo «de cuatro bodas complicadas y un posible funeral», en el que hemos tratado de poner gráficamente de manifiesto las posibilidades de que se implante con éxito el voto electrónico en España. Las «cuatro bodas» hacen referencia a las condiciones anteriores y el «funeral» a esta última, a la de la aceptación ciudadana.

$Y$ es que parece realmente difícil conseguir la aceptación de los ciudadanos. Es mucho, pues, lo que hay que hacer aquí. Hay que tener en cuenta que con el actual sistema de votación con papeletas cualquier persona, hasta la más ignorante, puede entender el proceso y forjarse la convicción de que el mismo ha sido limpio. Si hay algo transparente y a prueba de dudas en nuestro sistema político es el sistema de votación ${ }^{25}$ : las Mesas Electorales están formadas por ciudadanos elegidos por sorteo, y cuentan con presencia de los interventores de los partidos políticos; estas Mesas Electorales controlan el derecho a votar de los electores; éstos pueden confeccionar su voto en la cabina de votación y votan en un sobre cerrado que depositan en una urna transparente; la urna está todo el día bajo la custodia de la Mesa y cuando concluye la votación se pasa sin interrupción al escrutinio; éste es público; cuando termina el escrutinio se levanta un acta que se entrega en mano al Juez competente y se da copia a los interventores de los partidos y al representante de la Administración; a los pocos días la Junta Electoral competente realiza el escrutinio definitivo ${ }^{26}$.

Se podrían, quizás, manipular los resultados de algunas mesas, pero no de muchas, y ello difícilmente tendría, además, un efecto apreciable en la suma global; y podrá haber errores, sin duda, pero sin incidencia significativa en el conjunto.

23 El acuerdo político se logró con gran facilidad en 2004, con ocasión de la entonces posible introducción del voto electrónico en el referéndum europeo de febrero de 2005. Es difícil, sin embargo, que vuelva a darse un consenso semejante.

24 Vid., por ejemplo, VV.AA. (2009). El Informe del Consejo de Estado sobre la reforma electoral. Texto del Informe..., op. cit., págs. 258-259.

25 Vid. MEZO, J. (2004). «Inútil y peligroso», El País, 3 de octubre de 2004.

26 Sobre el actual sistema de votación vid. los artículos 27 a 29, 76 a 79 y 84 a 108 de la LOREG. 
Por el contrario, hay factores iniciales de signo opuesto: no vemos lo que hace la máquina y, además, bastaría un pequeño número de personas para hacer una gran manipulación (por ejemplo, por quienes diseñan las máquinas o por un grupo de hackers).

Ante este panorama, creemos que para lograr la aceptación ciudadana del voto electrónico es preciso que éste ofrezca niveles de cercanía, transparencia y confianza similares a los del sistema tradicional. Éste es el reto, el gran reto sin duda, que tiene ante sí el voto electrónico.

¿Y cómo conseguirlo? Para ello es necesario, a mi juicio, que el diseño del voto electrónico se ajuste al cumplimiento de una serie de condiciones o requisitos. Son, expuestos con suma brevedad, los tres siguientes:

1. Presencialidad. Que el voto electrónico que se implante sea, como regla general, presencial, directo, es decir, emitido en los colegios electorales, y no remoto o por internet ${ }^{27}$. El voto electrónico directo combina de modo muy adecuado las virtudes de la técnica, de la tecnología, de que he hablado antes, con las enormes ventajas que presenta el voto directo o por personación del elector en el colegio electoral que le corresponda, como el control por la Mesa Electoral de las condiciones de la votación, la conservación del principio de unidad del acto electoral o el mantenimiento de la liturgia democrática.

2. Verificabilidad. Que el voto que emiten los ciudadanos sea verificable, y ello tanto por parte del propio elector nada más confeccionar el voto, como, en general —en relación con el conjunto del electorado-, por la Administración Electoral después de las elecciones. Esto nos lleva a la introducción en el proceso de votación de uno de estos dos materiales de votación: bien la tarjeta con banda magnética, bien la existencia de un resguardo en papel que se deposita en otra urna. Esto es importante, pues actúa como una especie de paracaídas de emergencia del sistema ${ }^{28}$.

27 Esto no significa, sin embargo, que el voto por internet no deba tener ninguna aplicación. En modo alguno. Internet puede ser, ahora o en el futuro, a mi juicio, un instrumento válido de votación, sustituto del correo, en relación con todos aquellos electores que, por el motivo que sea, no pueden personarse en su colegio electoral el día de las elecciones, pero siempre, naturalmente, que se establezcan las medidas que sean precisas para eliminar o reducir sensiblemente sus limitaciones. Estoy pensando en ancianos y en discapacitados, y también en los españoles del exterior, dada las dificultades que plantea en este colectivo tanto el voto por correo, como el voto tradicional en urna. Sobre el fracaso de este sistema de votación en relación con los emigrantes vid. GÁLVEZ MUÑOZ, L. A. (2001). «El voto por correo: ¿una nueva reforma?», Revista de Derecho Político, núm. 52, págs. 249 y ss. (número monográfico sobre «el sistema electoral»).

28 Así, conviene recordar que la previsión del resguardo fue fundamental para la aceptación de los resultados en el referéndum revocatorio de 2004 del Presidente Hugo Chávez en Venezuela. 
3. Accesibilidad. Que se permita el acceso de partidos, especialistas y asociaciones representativas interesadas en esta cuestión en la organización, desarrollo y control del proceso. Hay que abrir de par en par las puertas de la cocina del voto electrónico, pues la opacidad o, al menos, el déficit de publicidad, puede generar sospechas y suspicacias de todo tipo, muy difíciles de atajar.

Además de ello sería sumamente conveniente, si no imprescindible, que a la hora de implantar el voto electrónico se actúe de forma gradual, escalonada, paso a paso, como se ha hecho en los países donde este instrumento de votación ha alcanzado mayo éxito ${ }^{29}$. Hay que dosificar, por tanto, cuidadosamente su introducción, pues, si no, se puede generar en los ciudadanos un sentimiento de rechazo al procedimiento, como ha pasado ya en algún país ${ }^{30}$.

Si se cumplen todas estas condiciones creemos que será posible evitar el funeral de que hablábamos antes y celebrar la boda, la boda más difícil, esto es, la ansiada unión o conciliación entre el voto electrónico y la ciudadanía. Éste es el reto que hay que conseguir. Tiempo habrá luego, tras el rodaje de los primeros años, de ajustar las condiciones de la vida en común, es decir, de introducir cambios en el diseño del voto electrónico en aras a mejorar su funcionamiento.

\section{BIBLIOGRAFÍA CITADA}

BARRAT ESTEVE, J. (2009). «Observación electoral y voto electrónico», Revista Catalana de Derecho Público, núm. 39.

FERNÁNDEZ RIVEIRA, R. Ma . (2001). «El voto electrónico: el caso vasco», Revista de Estudios Políticos, núm. 112, págs. 199-236.

FERNÁNDEZ RIVEIRA, R. Mª . (2005). «El incierto potencial derivado de la conjunción derecho de voto y nuevas tecnologías. El nuevo proyecto de ley de voto electrónico en Euskadi», en Nuevas Políticas Públicas: Anuario multidisciplinar para la modernización de las Administraciones Públicas, núm. 1, (ejemplar dedicado a Los derechos fundamentales y las nuevas tecnologías).

GÁLVEZ MUÑOZ, L. A. (2001). «El voto por correo: ¿una nueva reforma?», Revista de Derecho Político, núm. 52, págs. 249 y ss. (número monográfico sobre «el sistema electoral»).

${ }^{29}$ Es el caso, por ejemplo, de Brasil, donde el proceso de implantación del voto electrónico ha durado casi veinte años.

30 Ha habido varios casos de vuelta atrás, de abandono del voto electrónico y de regreso a la forma tradicional de votación. Hay ejemplos muy recientes como los de Holanda y Alemania, pero también anteriores como los de Filipinas, Japón o algunos Estados de los Estados Unidos como California. 
GÁLVEZ MUÑOZ, L. A. (2009). «Reflexiones sobre el voto electrónico en las elecciones autonómicas», en GÁLVEZ MUÑOZ, L. A. (dir.), El Derecho electoral de las Comunidades Autónomas. Revisión y mejora», Centro de Estudios Políticos y Constitucionales, Madrid.

GÁlVEZ MUÑOZ, L. A. (2009). La confección del voto, Centro de Estudios Políticos y Constitucionales, Madrid.

GONZÁLEZ DE LA GARZA, L. M. (2008). El voto electrónico por internet, Constitución y riesgos para la democracia, Edisofer, Madrid.

GUILLEN CARRAU, J. (2010). «El voto electrónico: régimen electoral o legislación electoral autonómica», Asamblea. Revista Parlamentaria de la Asamblea de Madrid, núm. 23.

MEZO, J. (2004). «Inútil y peligroso», El País, 3 de octubre de 2004.

PRESNO LINERA, M. A. (2007). «La globalización del voto electrónico», en COTINO HUESO, L. (coordinador), Democracia, participación y voto a través de las nuevas tecnologías, Comares, Granada.

RENIU VILAMALA, J. Ma . (2008). «Ocho dudas razonables sobre el voto electrónico», en Revista de Internet, Derecho y Política, núm. 6.

VV.AA. (2009). El Informe del Consejo de Estado sobre la reforma electoral. Texto del Informe y debates académicos, Consejo de Estado y Centro de Estudios Políticos Constitucionales, Madrid (también Informe del Consejo del Estado sobre las propuestas de modificación del régimen electoral general, de 24 de febrero de 2009, págs. 330-331, accesible en www.consejo-estado.es, consulta el 11-03-2011).

\section{Title}

The electronic voting (e-vote) and the quality test; or about four hazardous weddings and a likely funeral.

\section{Sumary}

I. The legislator's doubts regarding electronic voting. II. The quality test as an acceptability scrutiny of electronic voting. A) Technical safety or reliability. B) Guaranteeing the basic principles of suffrage. C) Harmonic integration within the electoral regime. D) Consensus or acceptance from those involved. E) Limiting costs. III. The possibilities of introducing electronic voting: challenges and strategies. IV. References.

\section{Resumen}

¿Qué posibilidades hay de implantar con éxito el voto electrónico en España? ¿Podría ser a medio plazo una realidad en las distintas elecciones políticas que se celebran en nuestro país? De la evaluación de esta importante cuestión se ocupa el presente trabajo, tomando como 
base las dudas mostradas por el legislador ante la maraña de oportunidades y problemas que confluyen en este terreno, y utilizando como guía de análisis la formulación de un test de calidad especifico, a modo de escrutinio de la aceptabilidad del voto electrónico. La conclusión a la que se llega es bastante abierta, habida cuenta la importancia que tiene tanto el diseño por el que se opte, como la estrategia de implantación que se siga.

\begin{abstract}
$¿$ What are the possibilities of a successful implantation of the electronic voting in Spain? Could it be a mid-term reality in the different kind of elections of our country? This paper will focus on this important topic, taking as a base the reservations of the lawmaker facing not only the opportunities but also the problems that gather here. We take as a guide a quality test drafted in order to get important information about the acceptability of the electronic voting. After this analysis, we get to an open conclusion due to the strategy of implantation and the design picked.

\section{Palabras clave:}

Participación política. Derecho electoral. Elecciones. Derecho de sufragio. Votación. Voto electrónico. Democracia electrónica.

\section{Key words}

Political participation. Suffrage Law. Elections. Suffrage right. Voting. E-vote. E-democracy.
\end{abstract}


